\title{
Effect of Process Parameters on the Surface Morphology and Mechanical Performance of Silicon Structures After Deep Reactive Ion Etching (DRIE)
}

\author{
Kuo-Shen Chen, Arturo A. Ayón, Senior Member, IEEE, Xin Zhang, Member, IEEE, and S. Mark Spearing
}

\begin{abstract}
The ability to predict and control the influence of process parameters during silicon etching is vital for the success of most MEMS devices. In the case of deep reactive ion etching (DRIE) of silicon substrates, experimental results indicate that etch performance as well as surface morphology and post-etch mechanical behavior have a strong dependence on processing parameters. In order to understand the influence of these parameters, a set of experiments was designed and performed to fully characterize the sensitivity of surface morphology and mechanical behavior of silicon samples produced with different DRIE operating conditions. The designed experiment involved a matrix of 55 silicon wafers with radiused hub flexure (RHF) specimens which were etched 10 min under varying DRIE processing conditions. Data collected by interferometry, atomic force microscopy (AFM), profilometry, and scanning electron microscopy (SEM), was used to determine the response of etching performance to operating conditions. The data collected for fracture strength was analyzed and modeled by finite element computation. The data was then fitted to response surfaces to model the dependence of response variables on dry processing conditions. The results showed that the achievable anisotropy, etching uniformity, fillet radii, and surface roughness had a strong dependence on chamber pressure, applied coil and electrode power, and reactant gases flow rate. The observed post-etching mechanical behavior for specimens with high surface roughness always indicated low fracture strength. For specimens with better surface quality, there was a wider distribution in sample strength. This suggests that there are more controlling factors influencing the mechanical behavior of specimens. Nevertheless, it showed that in order to achieve high strength, fine surface quality is a necessary requisite. The mapping of the dependence of response variables on dry processing conditions produced by this systematic approach provides additional insight into the plasma phenomena involved and supplies a practical set of tools to locate and optimize robust operating conditions.

[684]
\end{abstract}

Index Terms-Deep reactive ion etching (DRIE), fracture strength, MEMS, plasma etching, silicon, surface morphology.

Manuscript received April 23, 2001; revised September 26, 2001. This work was supported by the U.S. Army Research Office (ARO) and DARPA under Contract DAAH04-95-1-0093. This paper was presented in part at the MRS Fall Meeting, Boston, MA, 1998. Subject Editor H. Fujita.

K.-S. Chen is with the Department of Mechanical Engineering, National Cheng-Kung University, Tainan, Taiwan 70101 (e-mail: kschen@mail.ncku.edu.tw).

A. A. Ayón is with Sony Semiconductor, San Antonio, TX 78245 USA.

X. Zhang was with the Microsystems Technology Laboratories, Department of Electrical Engineering and Computer Science, Massachusetts Institute of Technology (MIT), Cambridge, MA 02139 USA. She is now with the Department of Manufacturing Engineering, Boston University, Brookline, MA 02446 USA.

S. M. Spearing is with the Department of Aeronautics and Astronautics, Massachusetts Institute of Technology (MIT), Cambridge, MA 02139 USA.

Publisher Item Identifier S 1057-7157(02)04976-4.

\section{INTRODUCTION}

D EEP reactive ion etching (DRIE) of silicon enables the microfabrication of high-aspect ratio structures (HARS), which, in turn, permit the fabrication of devices able to span from 100 to $1000 \mu \mathrm{m}$. HARS also allow the fabrication of structures that are compliant in the plane of the wafer but rigid in the direction normal to its surface [1]. Furthermore, HARS in combination with aligned silicon wafer bonding, make possible the realization of novel and promising applications, such as Power MEMS [2]. However, most applications place stringent requirement on HARS in terms of high silicon etching rate, good selectivity to masking material, profile control and compatibility with other processes [3].

STS licensed the DRIE technique patented by Robert Bosch Gmbh [4]. It relies on the deposition of inhibiting films to obtain anisotropic profiles. This approach utilizes an etching cycle flowing only $\mathrm{SF}_{6}$ [see Fig. 1, steps (ii) and (iv)] and then switches to a sidewall passivating cycle using only $\mathrm{C}_{4} \mathrm{~F}_{8}$ [see Fig. 1, step (iii) ]. During the subsequent etching cycle, the passivating film is preferentially removed from the bottom of the trenches due to ion bombardment, while preventing the etching of the sidewalls. The alternating of etching and passivating cycles forms scallops on the sidewalls of etched features. The peak to valley height of those scallops, being a function of operating conditions, can be controlled to some extent. Because of the alternating between etching and passivating cycles, the term time multiplexed deep etching (TMDE) describes more closely this technique and it will be used in all subsequent descriptions. The success of Bosch's TMDE scheme relies on the deposition of the inhibiting films to prevent the etching of the sidewalls.

The Bosch approach uses the high etching rate of fluorine-rich plasmas to etch HARS. Some recently reported applications are already exploiting this last alternative [1], [5], [6]. Furthermore, by suppressing the time multiplexing, the equipment can be run with continuous flows of $\mathrm{SF}_{6}$ or $\mathrm{C}_{4} \mathrm{~F}_{8}$. With $\mathrm{SF}_{6}$ it is possible to achieve isotropic profiles. With $\mathrm{C}_{4} \mathrm{~F}_{8}$ it is possible to deposit teflon-like films that have been described elsewhere [7]. The large parameter space for a DRIE etching tool has proven to be versatile enough to allow prescribing the profile of etched features, uniformity across the wafer, selectivity to masking material, silicon etching rate as well as surface roughness.

As mentioned before, power MEMS is one important application of HARS. The favorable scaling of the strength of brittle 


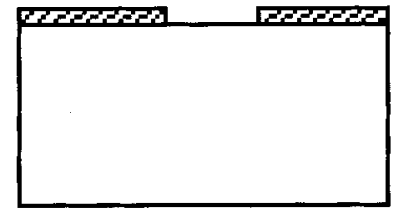

(i)

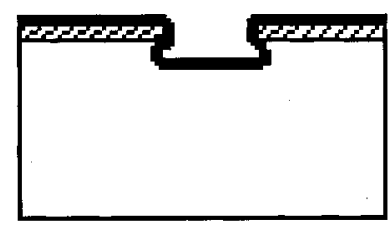

(iii)

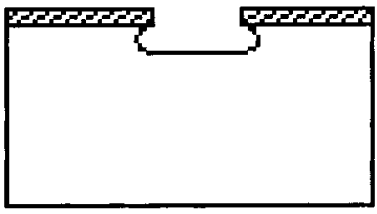

(ii)

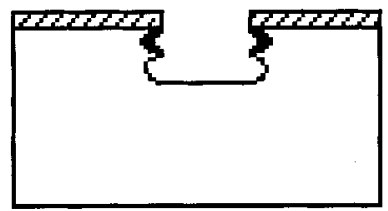

(iv)
Fig. 1. TMDE scheme. (i) Patterned masking material on a silicon wafer (ii) Silicon etching cycle. (iii) Fluorocarbon film deposition. (iv) Silicon etching cycle.

materials offers the potential to create MEMS capable of operating at high power densities. Such devices could be used for electrical power generation, propulsion, flow control, pumping or local cooling. In order to achieve useful power levels, these machines require characteristic dimensions in the range from 0.1 to $10 \mathrm{~mm}$. Examples under development at MIT include micro gas turbine engines, micro motor compressor, micro rocket engines [8], and micro solid-state hydraulic transducers [9]. The success of these power MEMS relies on achieving high mechanical strengths and the capability of controlling local stress levels. At temperatures below about $800 \mathrm{~K}$ silicon is a brittle, elastic material with an extremely high ideal strength and low fracture toughness [10], [11]. The low toughness implies a strong sensitivity of strength on processing conditions and the presence of induced flaws or cracks. The performance of a DRIE tool was investigated by Ayón et al. [12]. They found that the etch rate and the anisotropy were strongly influenced by the etching parameters. By varying these parameters, it is possible to obtain a suitable recipe for a particular application. In parallel, the surface morphology and fracture strength of silicon after DRIE have been studied by Chen et al. [13]. They investigated the strength of planar biaxial silicon specimens and silicon specimens with fillets hereby referred to as RHFS [14]. The reference fracture strength of planar silicon specimens was found to range from 1.2 to $4.6 \mathrm{GPa}$ with a Weibull modulus ranging from 2.7 to 12 . This reported strength and distribution agreed with some previous investigations at similar scale [15] and the strength was slightly higher than most found in another study at a smaller length scale and different surface treatment [16]. However, the strength of RHFS was only around $1.5 \mathrm{GPa}$ (with a Weibull modulus of 9) due to surface roughening in the fillet region. Chen et al. also found that by performing a short secondary isotropic etch to remove the surface $2-3 \mu \mathrm{m}$ on the silicon substrate, the fracture strength can be recovered to around $60-80 \%$ of the test strength of biaxial specimens.

Ayón et al. [7], [12] have demonstrated the capability to control the etching performance and trench profile by adjusting etching parameters. On the other hand, Chen et al. [13] have demonstrated that the fracture strength of silicon after DRIE could be acceptable for many applications. However, two issues remained unsolved. First, the work performed by Chen et al. focused on a particular set of operating conditions which was typically used for micro turbine-engine development. The sensitivity of fracture strength versus a wider range of process parameters was not investigated. Second, from the MEMS system design point of view, an optimal process parameter set should yield both satisfactory results in both microfabrication performance and material strength. As a result, it was important to conduct a systematic investigation to find the sensitivity of surface morphology and mechanical strength on processing conditions.

Experimental studies [7], [12] suggested that the achievable fillet radii, surface quality, and etch rate are functions of the etch conditions such as the flow rate of $\mathrm{C}_{4} \mathrm{~F}_{8}$ and $\mathrm{SF}_{6}$, electrode power, chamber pressure, and etching cycle duration. In order to optimize the fabrication process design, it is necessary to build the corresponding database to address the sensitivities of fabrication performance on etching parameters. To facilitate the understanding of the observed characteristics, the development of such a database via a systematic parametric study of DRIE parameters is required.

This paper discusses the study of sensitivity of etching performance on processing conditions. This parametric study utilized 55 silicon wafers etched with different etching process parameters. Each silicon wafer contained 25 RHF specimens [14]. Etching rate, uniformity, anisotropy, profile control, resulting fillet radii, surface roughness, and fracture strength from these specimens were measured. Finally, data reduction was performed in order to establish the sensitivity of those variables on processing parameters.

This paper is organized as follows: the experimental plan is addressed in detail in Section II. The etching related performance variables, including etching rate and surface morphology, are discussed in Section III. Fracture strength as well as other mechanical characteristics of silicon samples after DRIE will be covered in Section IV. Section V discusses some of the applications of this study. Finally, Section VI summarizes the results and presents the final conclusions.

\section{EXPERIMENTAL APPROACH}

The goal of this study was, therefore, to explore the sensitivity of etching performance on processing parameters and to provide guidance for locating optimal etching conditions for MEMS fabrication utilizing DRIE. The performance variables to be measured or tested included silicon etching rate, anisotropy, uniformity, surface morphology and fracture strength. In this study, the processing parameters were chosen systematically and 50 sets of operating conditions were created. These 50 recipes were then used to etch 55 wafers. The extra five wafers were etched using operating conditions within the matrix of 50 in order to evaluate the repeatability of the etches. Each wafer contained 25 planar biaxial and 25 RHF specimens. Since the etching rate of silicon in DRIE is around $1-3 \mu \mathrm{m} / \mathrm{min}$, 
TABLE I

PROCESS CONTROLLED PARAMETERS FOR INVESTIGATION

\begin{tabular}{l|l|l}
\hline \multicolumn{1}{c|}{ Reactants Supply } & Plasma Power Conditions & Etch/Passivation Adjustment \\
\hline $\mathrm{SF}_{6}$ flow rate & $\bullet$ Electrode power during & $\bullet$ Etching cycle \\
& $\mathrm{C}_{4} \mathrm{~F}_{8}$ flow rates & $\bullet$ Passivation cycle \\
& $\bullet \begin{array}{l}\text { Coil power } \\
\text { Electrode power during } \\
\end{array}$ & \\
& passivation \\
& APC positions & \\
\hline
\end{tabular}

the etching time for each wafer was fixed at $10 \mathrm{~min}$ and a 10-30 $\mu \mathrm{m}$ each depth was expected. Although the etch depth was much smaller than that for typical DRIE etched MEMS structures, the results were useful for building the sensitivity models to predict the behavior of silicon samples after DRIE.

This work was performed using a Surface Technology Systems Multiplex ICP (STS Multiplex ICP STS Made in Redwood, CA Serial \# 041, Vacuum pumping Chamber is done by Balzers TMH 1000C (Pfeiffer Vacuum Technology), Hudson, $\mathrm{NH}$ ) [17]. The equipment included two independent $13.56 \mathrm{MHz}$ RF power sources: one for the coil around the etching chamber to create the plasma, and another connected to the wafer electrode to control the RF bias potential of the wafer with respect to the plasma. Backside helium pressurization was used to provide sufficient heat transfer between the wafer and the electrode to maintain a constant wafer temperature. A set of eight alumina fingers clamped the wafer to the electrode. The measured temperature on the surface of the wafer during processing was $40{ }^{\circ} \mathrm{C}$. This was monitored using temperature sensitive dot strips mounted on the surface of the wafer. At this temperature, the etching rate of the photoresist was reduced and allowed its use as a mask for etching silicon. It was possible to operate with a predetermined common pressure for both etching and passivating active cycles, or with a fixed angular position for the throttle or automatic pressure control (APC) valve. In the first case the position of the APC valve varied as the gas flow changed during each cycle. In the latter case, the position of the throttle valve was fixed and the pressure was determined by the gas flow rate. The results presented in this paper used this latter approach. Higher values of the APC valve position in degrees corresponded to higher chamber pressures. However, the trip pressure was fixed at $90 \mathrm{mT}$ creating an upper chamber pressure limit in these experiments. Another variable influenced by the gas flow rate is the residence time, $\tau$, which is proportional to $p V / f$, where $p$ is the chamber pressure, $V$ the chamber volume and $f$ the gas flow rate. This time is important in relation to the removal rate of etching byproducts in the process chamber with the corresponding effect on reactant concentration [18], as well as in the replenishing of etching species. Thus, APC positioning and gas flow rate influence the etching characteristics. The variables explored are listed in Table I.

The specimens were prepared in the following fashion: $400-\mu \mathrm{m}$ thick, 4-in single crystal silicon $\langle 100\rangle$ wafers, n-type with resistivity between 6 and $20 \Omega-\mathrm{cm}$, were coated with

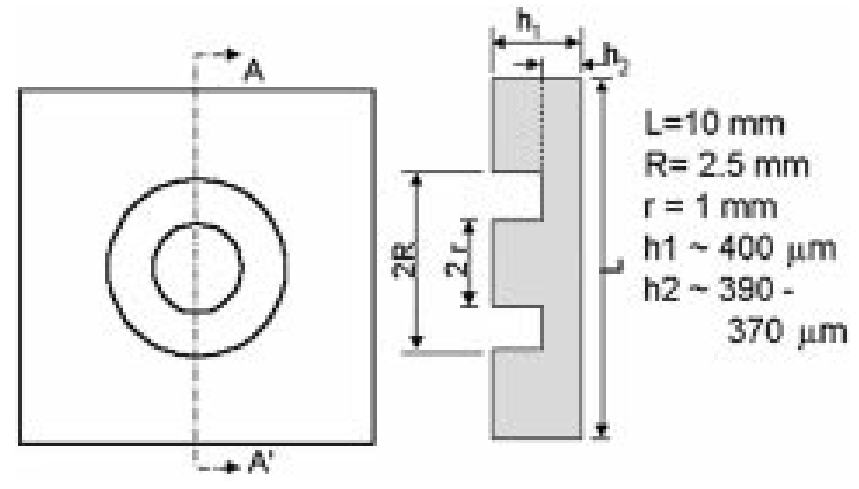

(a)

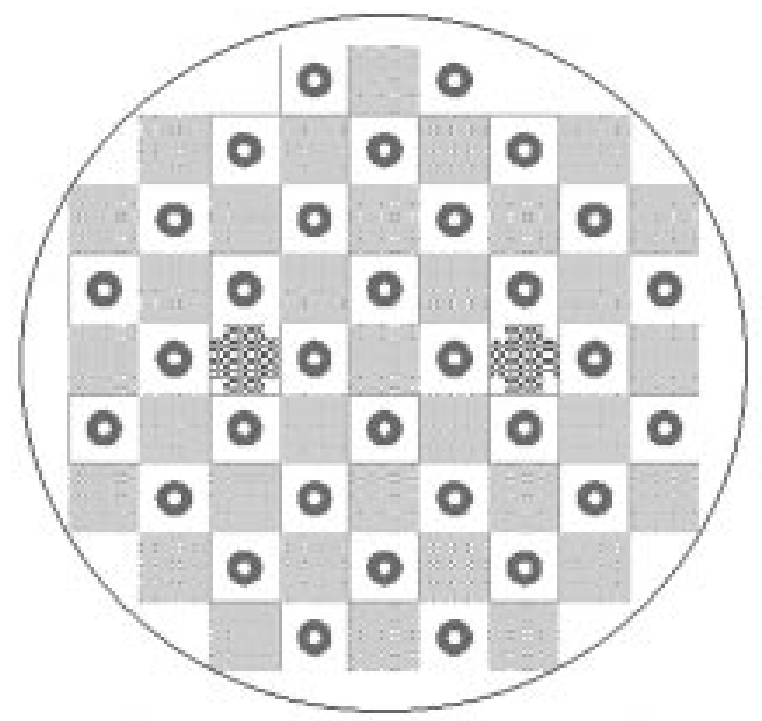

(b)

Fig. 2. (a) The RHF specimen design and (b) final layout of the entire wafer.

photoresist, exposed to a mask that uncovered $18 \%$ of the total wafer area, and developed. The photoresist removal rate was determined by measuring the photoresist thickness before and after the etch with an optical interferometer. Additionally the depth achieved and the uniformity across the wafer were measured using a DEKTAK profilometer and SEM inspection. The actual thickness of each wafer was also measured by a micrometer.

Once the samples were prepared, the designed set of experiments adequate to fit a quadratic model was performed and analyzed using the commercial software package ECHIP (a registered trademark). The measured data was fitted and the corresponding response surfaces were generated [18]-[20]. The preliminary validation of the model was determined by recording the adjusted $R^{2}$ of each variable. The adjusted $R^{2}$ is always $\leq 1$ and it is a measure of the fit of the curve to the data. Higher values indicate a better data fit. Additional validation criteria included the comparison of predicted and measured values on arbitrary operating conditions selected by the user and the comparison of predicted and measured values using processing conditions suggested by the model. The large parameter space presented in this paper obviates the necessity for the utilization of response surfaces as required tools to assess the combined effect of modifying operating conditions. Without this aid, the final 


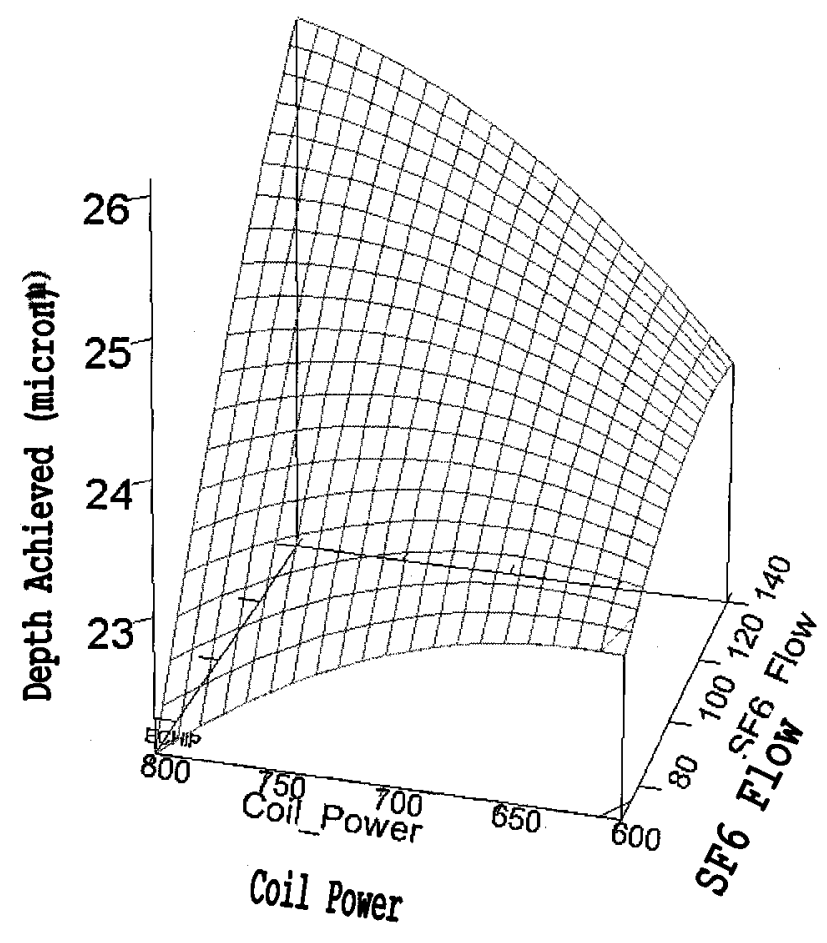

Fig. 3. Total depth achieved as a function of $\mathrm{SF}_{6}$ flow rate $(\mathrm{sccm})$ and applied coil power $(\mathrm{W})$.

outcome after modifying operating conditions is difficult to predict.

For the mechanical strength determination, as shown in Fig. 2(a), the RHF specimen design consists of square dies of $1 \mathrm{~cm}^{2}$ in size. An annular region with inner and outer radii of 1 and $2.5 \mathrm{~mm}$ was etched. There were 25 RHF specimens per wafer. Due to the stochastic nature of the fracture strength of brittle materials, relatively large numbers of specimens are required to obtain the strength in a statistically acceptable manner. The schematic layout of the entire wafer is shown in Fig. 2(b). 15 to 20 RHF specimens per wafer were mechanically tested to determine the fracture strength. For the rest of the specimens, two were used for measuring the etching rate, and the remainder were used for SEM inspection and AFM measurements. The fillet radii at the trench bottom, were defined as the smallest radius of curvature at the trench fillet region. This is an important parameter, since it defines the local stress concentration, the values were estimated by fitting a circle to SEM images. In some cases, the etch resulted in an elliptical, not a circular shape. In these situations, the semi-minor axis was treated as the fillet radius. The fracture load, combined with measurements of wafer thickness, etched depth, and the local fillet radius were used to construct finite element models to convert the fracture loads to fracture strengths [13].

Surface roughness measurements were taken with a Digital Instruments D3000 AFM using tapping mode. The scanned area was a square of $10 \mu \mathrm{m}$ per side; multiple readings were taken from each die in various locations between the hub and the outer wall. Dies from each wafer were cleaved to provide a cross section of the trench profile and these were examined using SEM, all with the same magnification of $20000 \times$. Curves were fit to determine the fillet radius at the etch base. The size of the scallops on the vertical walls were also measured, and averaged over 20 to 30 scallops per die.

\section{ETCHING RATE AND SURFACE MORPHOLOGY}

\section{A. Silicon Etching Rate}

Fig. 3 shows the etched depth achieved as a function of applied coil power and $\mathrm{SF}_{6}$ flow rate for samples exposed 10 minutes to the glow discharge. All measurements graphed in Fig. 3 were taken for trenches of a nominal width of $64 \mu \mathrm{m}$. This width was chosen because this size is small enough to avoid loading effects while it is sufficiently large so as to avoid problems occurring in deep etching due to mass transportation of the etchant and etching byproducts. These issues are discussed in more detail elsewhere [12].

The adjusted $R^{2}$ of the quadratic model for this response was 0.91 indicating that the fit was reasonably good [18]. The silicon etching rate increases with coil power because the ion flux density increases. Similarly, the etching rate increases with $\mathrm{SF}_{6}$ flow rate because of increases in the concentration of etching species $(F)$ and because of a reduction of etching products $\left(\mathrm{SiF}_{4}\right)$ that redeposit [21]. Although not shown here, silicon etching rate could also be increased by increasing the applied electrode power during the etching cycle. This is due to the increase in ion bombardment energy that results in higher etching rates. As the flow rate increases, the etching rate increases with both coil and electrode power [22].

The etching rate also increases with increases in the duration of the etching cycle due to longer exposures to the glow discharge. It also increases when the duration of the passivating cycle decreases due to thinner fluorocarbon film depositions. Chamber pressure also has a significant influence on etching rate, which initially increases with pressure due to higher $F$ concentrations [23], but as pressure increases even further, the ion energy and/or ion flux is reduced and the etching rate drops.

\section{B. Photoresist Etching Rate}

Low photoresist removal rate is necessary for a robust operation. Fig. 4 shows the photoresist etching rate dependence on applied electrode and coil power with TMDE suppressed. The photoresist etching rate increases with applied electrode power because of increases in ion bombardment energy, therefore, increasing ion bombardment improves the etching anisotropy but reduces the selectivity. During TMDE operation, this response is also sensitive to pressure and the duration of the etching and passivating cycles.

Although photoresist etching rate decreases as the pressure increases, there are several other important implications associated with large settings of the APC, namely, the sputtering and redeposition of masking material which promotes the formation of micro-columns or "grass" [20], the damage of structures (see Fig. 5) and excessive polymer deposition. These considerations limit the range of useful settings to no more than $75^{\circ}$. The duration of the active etching cycle determines the exposure time of the masking material during the etch and therefore the longer the cycle, the more the photoresist is etched. Similarly, during 


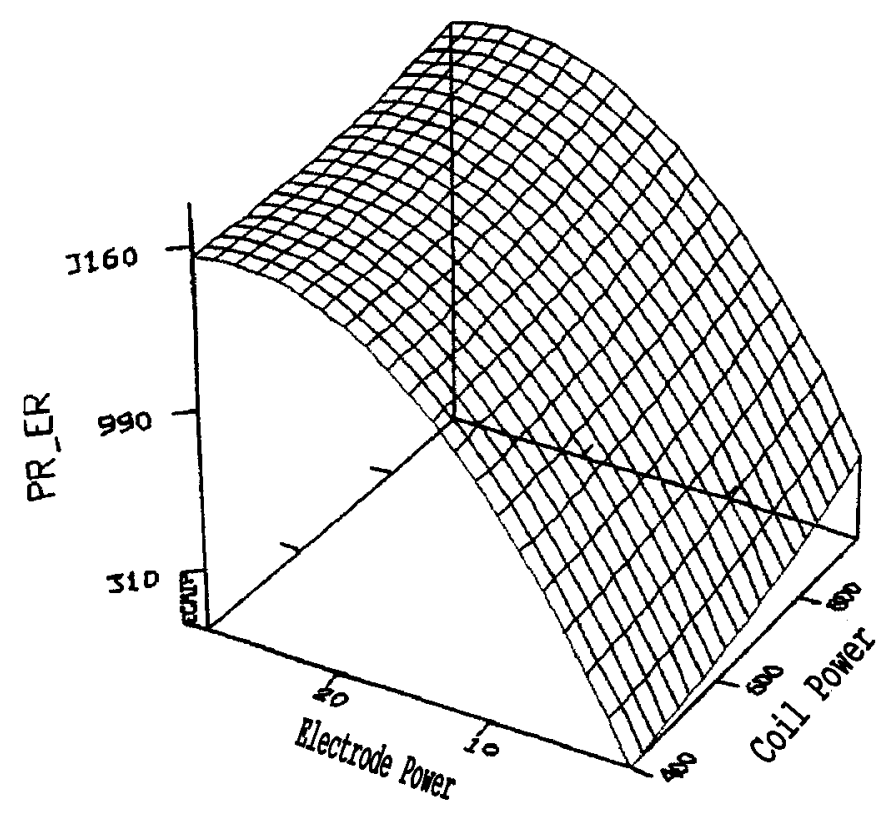

Fig. 4. Photoresist removal ( $\AA$ ) as a function of electrode power (W) during the etching cycle and coil power (W). The adjusted $R^{2}$ for this variable is 0.88 , which indicates a good fit.

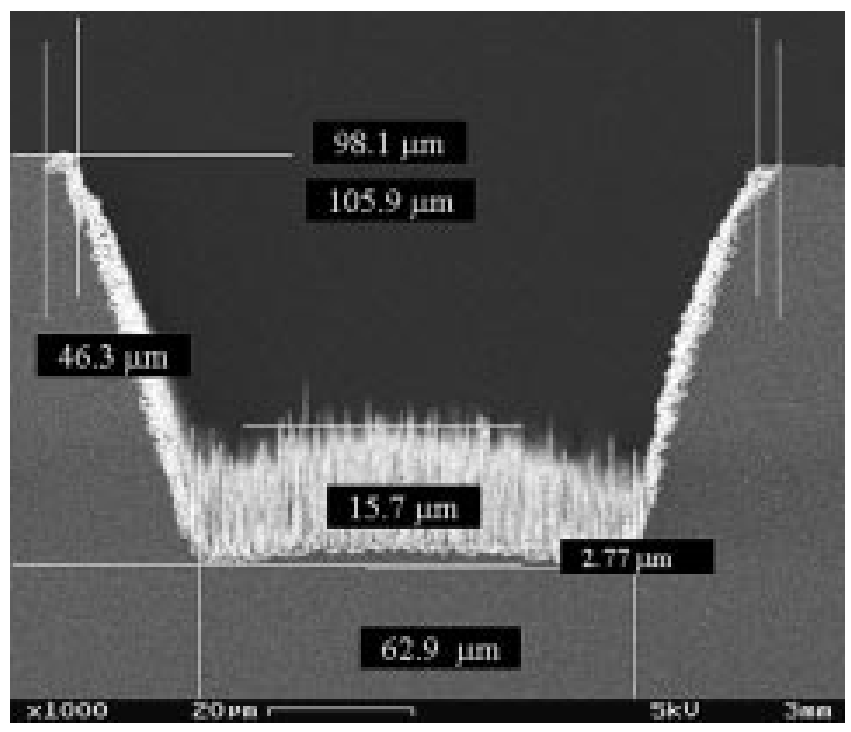

Fig. 5. SEM micrographs showing the deleterious effects observed with high settings of the APC. Results obtained with the APC set at $80^{\circ}$.

the passivating cycle the thickness of the polymerization film increases with time, thereby decreasing the photoresist removal rate with increasing passivation cycle time.

\section{Uniformity}

The variation of etch rate uniformity with $\mathrm{SF}_{6}$ flow rate and pressure is shown in Fig. 6. Plotted values were obtained by comparing the depth of trenches of nominal width of $64 \mu \mathrm{m}$ in the middle of the wafer ( $\left.h_{\text {middle }}\right)$, with trenches located $30 \mathrm{~mm}$ away $(h)$ and expressed by the equation: uniformity $=$ $\left(h / h_{\text {middle }}-1\right) \times 100 \%$.

This variable determines the extent of overetching required to achieve a prescribed depth across the wafer. Although this response is influenced by the temperature uniformity across the

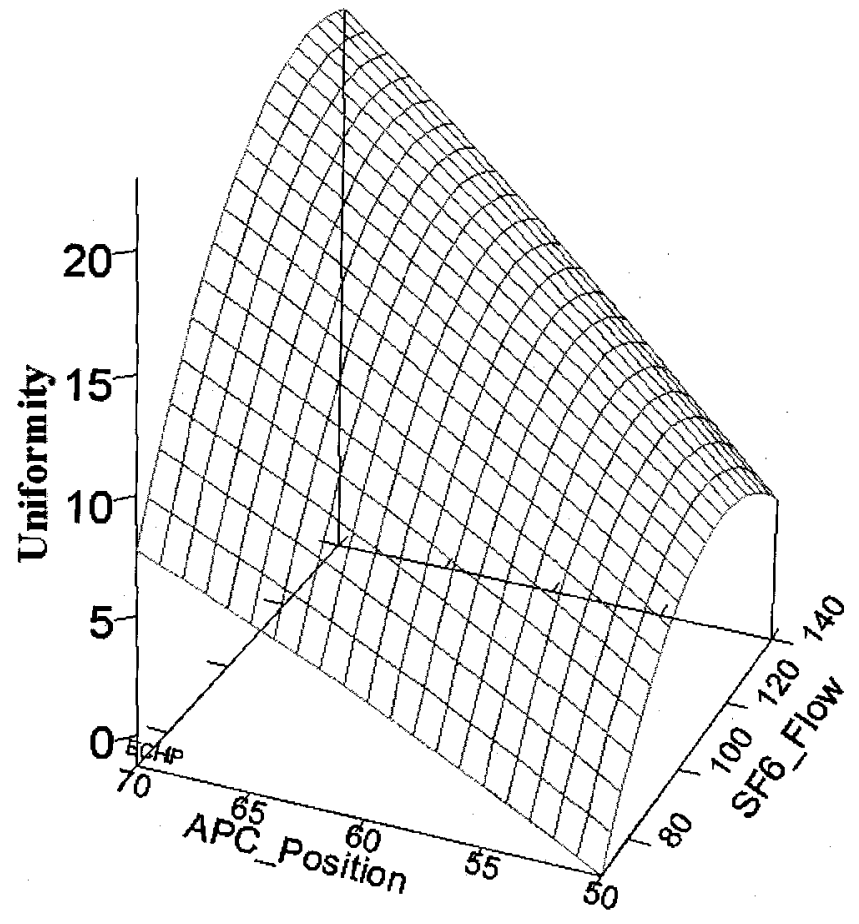

Fig. 6. Variation of etching rate uniformity with $\mathrm{SF}_{6}$ flow rate $(\mathrm{sccm})$ and $\mathrm{APC}$ valve position in degrees.

wafer, the local rates of plasma density loss and formation, the exposed area (i.e., the loading effect), and the feature density, etc., we can significantly simplify this picture by focusing on plasma formation. Thus, the plasma density being higher at points closer to the RF power coil or heating source, promotes local increases in the etching rate. Therefore, for most operating conditions the etching rate will be higher on the periphery of the wafer compared to points closer to the center of the wafer. Uniformity benefits from lower APC valve settings because the diffusivity varies inversely with the pressure. Thus, as the APC position is lowered, pressure drops, which results in increased diffusivity and improved uniformity [24]. Therefore, higher diffusivities reduce the plasma nonuniformity providing a better distribution of the ion flux to the wafer. The diffusive gas transport of the neutral reactants is also increased, reducing concentration gradients in the gas phase and producing a more uniform neutral flux on the surface. Similarly, uniformity benefits from lower $\mathrm{SF}_{6}$ flow rates because, for a fixed position of the APC valve, pressure decreases when the flow rate decreases.

\section{Anisotropy and Profile Control}

This response is of importance in every application, and the ability to tailor the slope of trench walls is one of the more important characteristics of this deep silicon etching tool. It is feasible to obtain anisotropic profiles [see Fig. 7(a)], positive slopes [see Fig. 7(b)] as well as reentrant profiles [see Fig. 7(c)] by changing etching parameters.

Anisotropy has a strong dependence on several variables such as coil and electrode power, the duration of the etching and passivating cycles, and chamber pressure. In general the combination of ion bombardment in conjunction with the formation and 

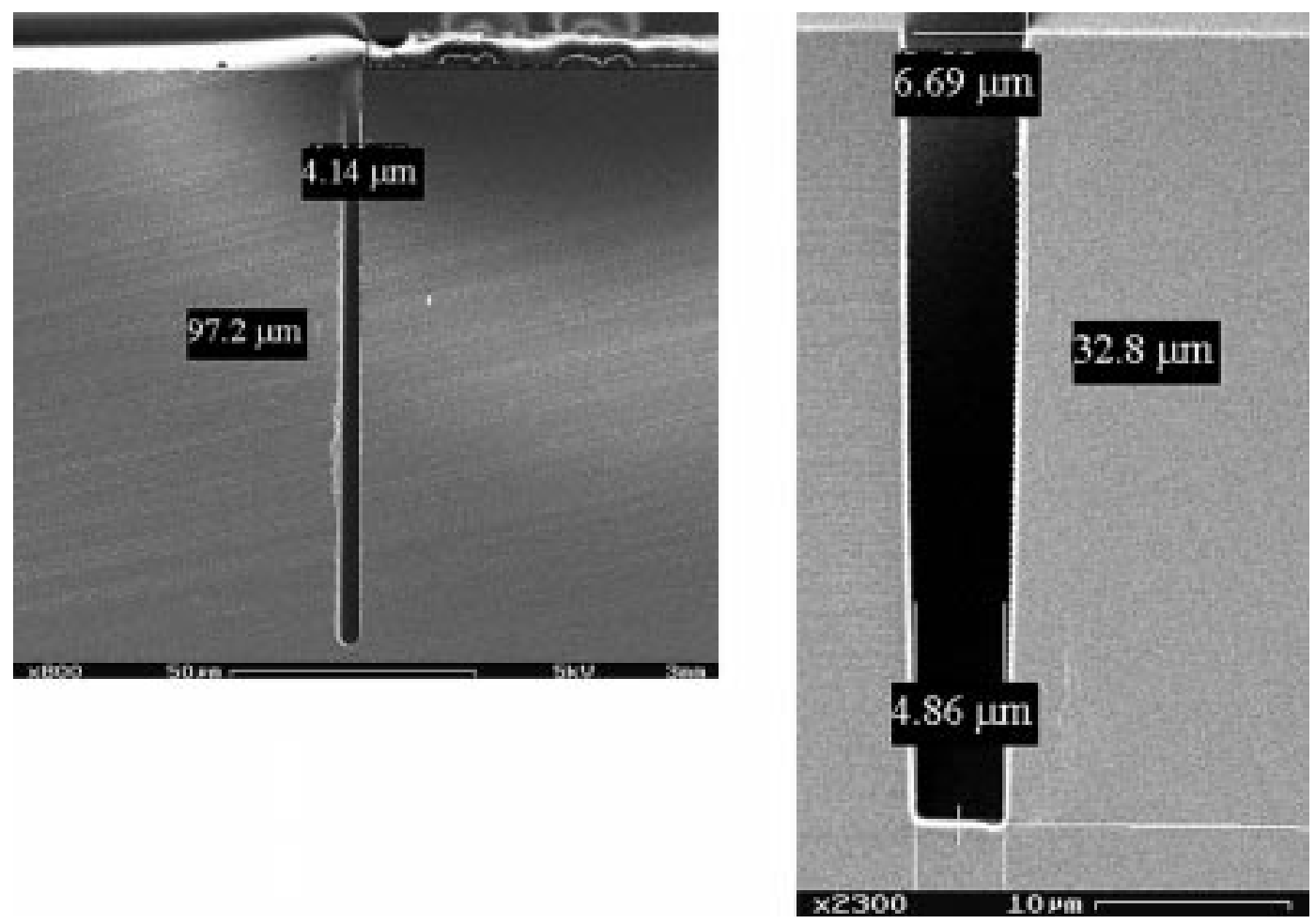

(a)

(b)

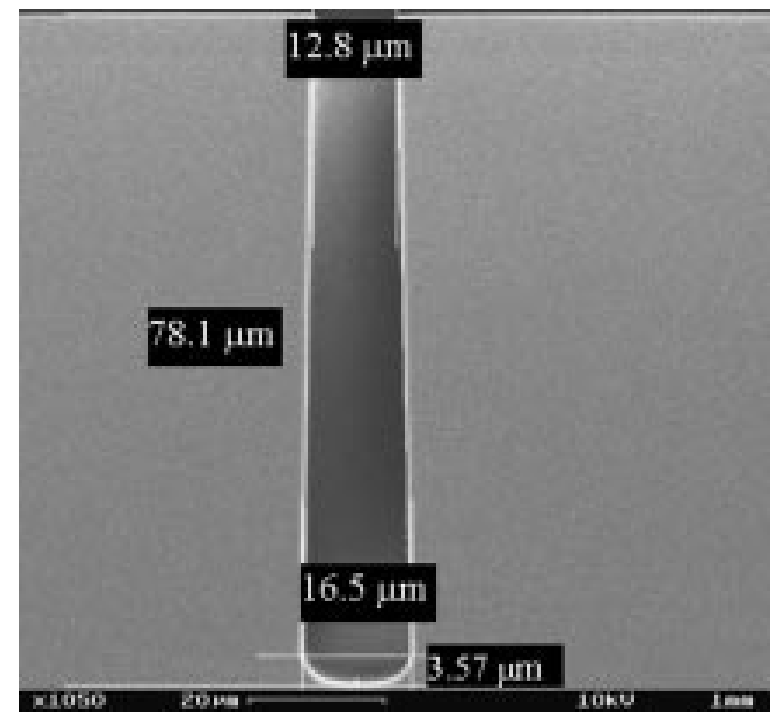

(c)

Fig. 7. (a) Deep trench in silicon with aspect ratio of 24 and a depth of nearly $100 \mu \mathrm{m}$. (b) Trench of $32.8 \mu \mathrm{m}$ deep with a noticeable positive slope: $6.69 \mu \mathrm{m}$ at the top and only $4.86 \mu \mathrm{m}$ at the bottom. (c) Trench of $78.1 \mu \mathrm{m}$ deep with a noticeable negative slope: $12.8 \mu \mathrm{m}$ at the top and $16.5 \mu \mathrm{m}$ at the bottom.

preservation of protective films on the sidewalls, allow us to achieve prescribed anisotropy and selectivity targets [25]. This is clearly illustrated, for instance, in the duration of the etching cycle with respect to the passivating cycle. An etching cycle too long with respect to the passivating cycle will promote reentrant profiles because etching continues long after the protecting film has been removed.

Similarly, if an etching cycle is too short it will not remove completely the deposited passivating films producing walls with significant surface roughness and other deleterious artifacts such as micromasking and grass formation. Thus, settings that promote the deposition of thicker passivating films, i.e., higher pressure, or that promote the efficient removal of such films, i.e., higher coil or electrode power, have a significant impact on anisotropy. For instance, with higher pressure settings the average ion energy is reduced, the angle of incidence of ions increases and the anisotropy deteriorates. A similar observation is made with increases in $\mathrm{SF}_{6}$ flow rate when operating with a fixed position for the APC valve. As the flow rate increases, the pressure rises and the anisotropy deteriorates. With higher 


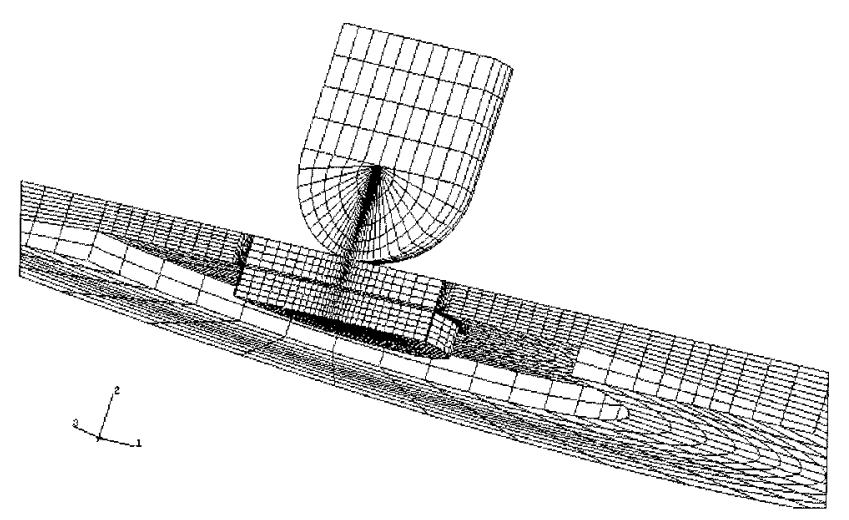

Fig. 8. The finite element mesh for the RHFS specimen and the indenter.

coil power settings the ion flux density increases, the removal of the passivating films is more complete and the anisotropy improves. Also, with higher electrode power settings the energy of ions bombarding the surface increases and the anisotropy can improve depending on the pressure being used.

It was generally observed that narrow and wide trenches do not exhibit the same anisotropy. Taking as a reference a particular trench, wider trenches become increasingly more reentrant. Thus, it is possible for trenches of dissimilar width to have sloped walls that are positive in one case (narrow trench) and negative in the other (wider trench).

\section{Fracture StRENGTH}

Our previous work [12] identified fillet radii at the bottom of trenches as a high failure probability site. This is reasonable because it has the highest stress level and tends to have the highest surface roughness. The scallops, as shown in Fig. 9(b), did not contribute the failure of test specimen due to relatively low stress (the stress level is only around $5 \%$ of that at trench fillet).

In order to find the fracture strength of silicon, the test data (load) must be converted to strength through finite element modeling. It should be noted that different etching conditions yielded different surface morphology and mechanical behavior. In addition, there was a $\pm 20 \mu \mathrm{m}$ possible thickness variation on each one of the wafers nominally $400 \mu \mathrm{m}$ thick. These issues made it impossible to construct a single finite element model. Instead, individual models had to be created based on the measurements of wafer thickness, silicon etching rate, and fillet radius. As shown in Fig. 8, the fracture strength was determined by finite element analysis with the fracture load as input [14], [26].

The measured strength varied from each batch and even between individual specimens. Since the strength of brittle materials is a stochastic variable, Weibull statistics is usually used for characterizing the fracture strength of brittle materials, which can be expressed as [27].

$$
P_{f}(\sigma, A)=1-\exp \left(\frac{A}{A_{0}}\left(\frac{\sigma}{\sigma_{0}}\right)^{m}\right)
$$

where $P_{f}$ is the failure probability, $A_{0}$ is the reference surface area, and $\sigma$ is the applied tensile stress. The Weibull modulus, $m$, and the reference strength, $\sigma_{0}$, can be obtained from a set of mechanical test data. They are indicators of material strength

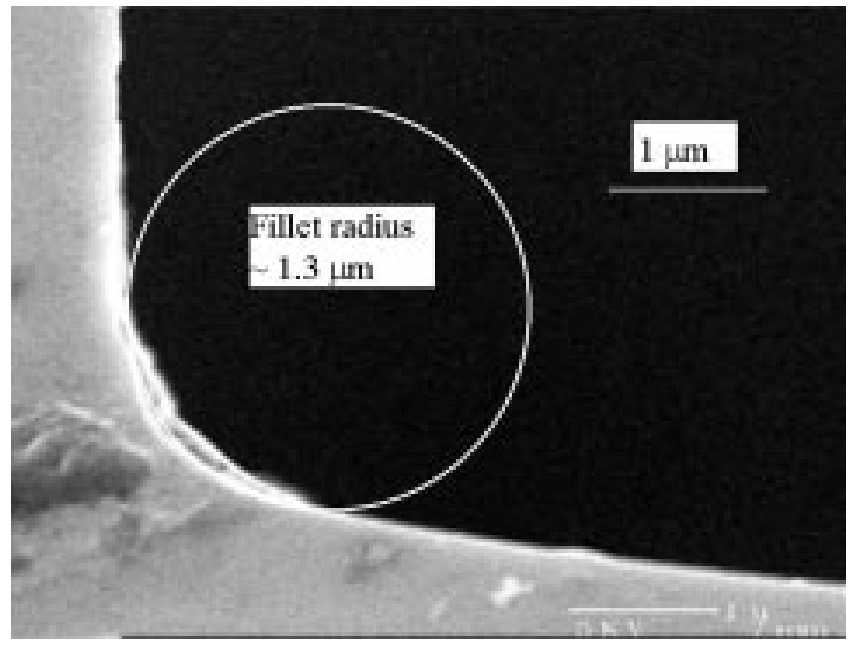

(a)

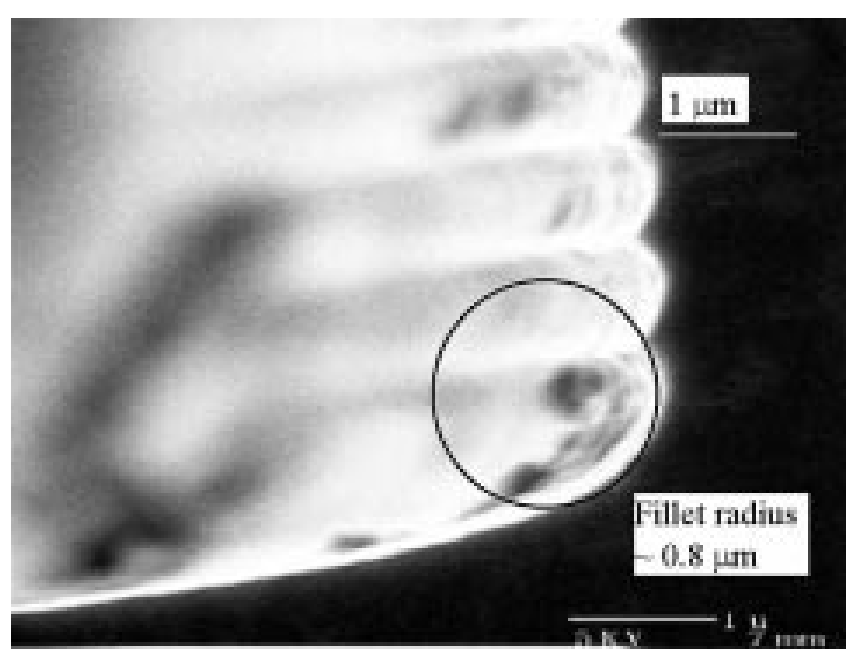

(b)

Fig. 9. SEM image of fillet radius achieved (a): by recipe \#21 and (b) by recipe $\# 40$. Fillet radius was determined by fitting a circle to SEM images and was defined as the smallest radius of curvature in the trench region.

and strength uniformity. The software package CARES/LIFETM developed by NASA was used to calculate these parameters [28].

The fillet radius is also a function of etch depth. Since the etch time was 10 minutes, the resulting fillet radii were small. Based on SEM observations, the radii varied between $0.5 \mu \mathrm{m}$ to $2.5 \mu \mathrm{m}$ as shown in Fig. 9. The AFM root mean square and peak-to-peak surface roughness measurement after DRIE varied between 5 to $50 \mathrm{~nm}$ and 50 to $400 \mathrm{~nm}$, respectively. Fig. 10 is a typical AFM image of a $20 \mu \mathrm{m} \times 20 \mu \mathrm{m}$ surface area of a specimen etched by a particular recipe. The average surface roughness is $5 \mathrm{~nm}$.

The fracture strength also showed considerable scatter with reference strengths between $900 \mathrm{MPa}$ to $3 \mathrm{GPa}$ and Weibull moduli between 1.9 to 5 . These low moduli indicated a considerable scatter in strength uniformity. Fig. 11 shows a typical Weibull plot for mechanical testing. The surface roughness, fracture strength, and Weibull moduli were correlated with process parameters by the commercial software package ECHIPTM. 


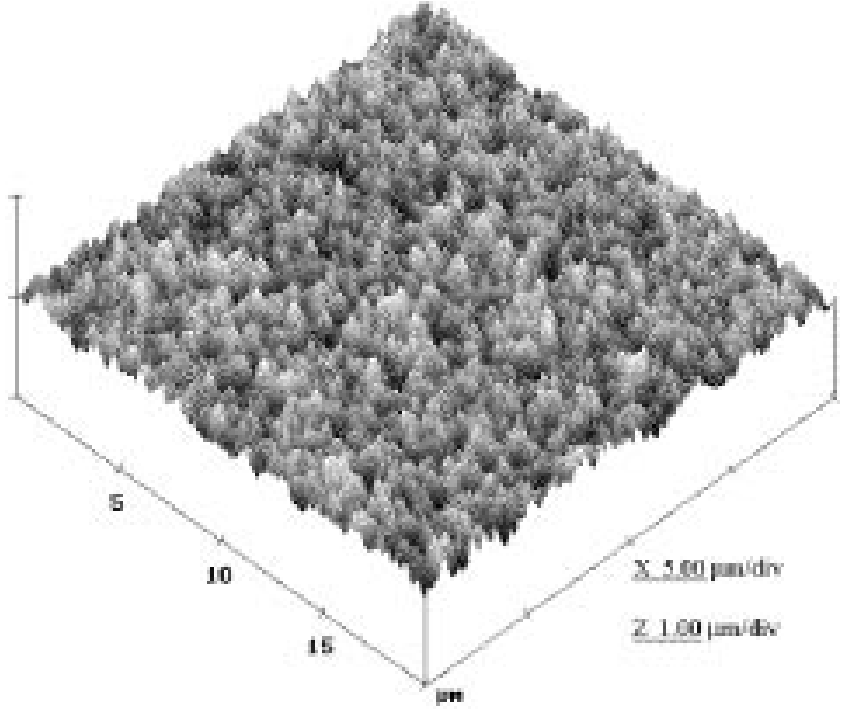

Fig. 10. A typical AFM surface image of silicon after DRIE. The average surface roughness is approximately $10 \mathrm{~nm}$.

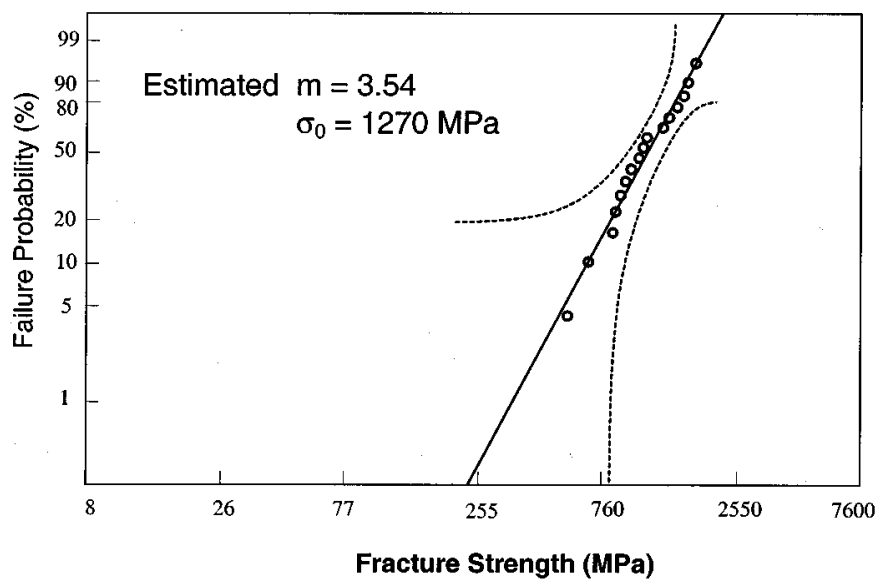

Fig. 11. A typical Weibull plot of silicon strength after processing by DRIE Results for 16 specimens are shown.

\section{A. Correlation Between Surface Morphology and Operating Conditions}

For certain applications, especially those involving structures subjected to high speeds or high stresses, the radius of the feature bottom (also known as fillet radius) determines the strength of the specimens involved, and the ultimate performance of those structures. Thus, it is important to have the ability to tailor this response. Fig. 12 shows the correlation of achievable fillet radius to the electrode power and the APC position as well as the $\mathrm{SF}_{6}$ flow rate. The plot shows that higher APC positions and lower electrode power will result in larger fillet radii. Low electrode power settings result in less energetic ion bombardment and the etching becomes less anisotropic. Higher APC positions correspond to higher chamber pressure. At higher chamber pressure, the availability of fluorine increases and the etch becomes more isotropic. In addition, higher $\mathrm{SF}_{6}$ flow rates represent more isotropic etching. The combination of low electrode power, high pressure and high $\mathrm{SF}_{6}$ flow rates permit the achievement of larger fillet radii. A relatively small fillet radius can be generated at low pressure settings as can be

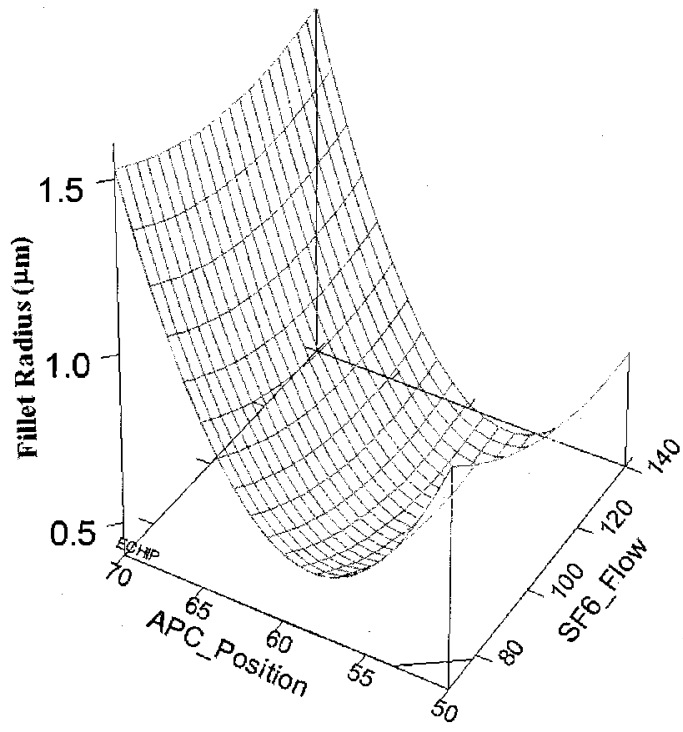

(a)

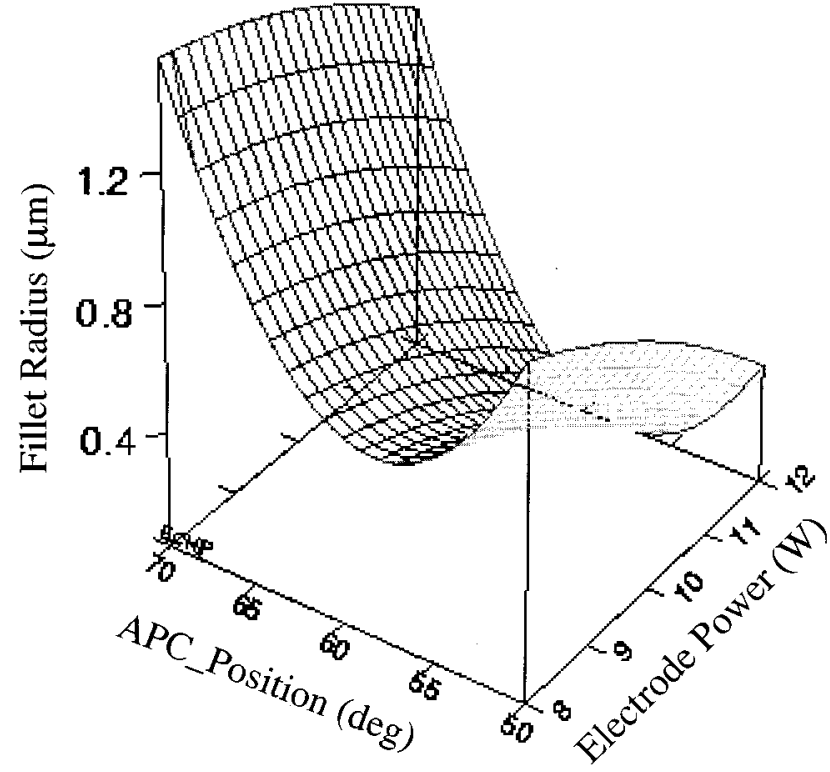

(b)

Fig. 12. Fillet radius $(\mu \mathrm{m})$ dependence on (a): $\mathrm{APC}$ position $\left({ }^{\circ}\right)$ and $\mathrm{SF}_{6}$ flow rate $(\mathrm{sccm})$ and $(\mathrm{b})$ : APC position $\left({ }^{\circ}\right)$ and electrode power $(\mathrm{W})$.

seen in Fig. 13(a). Similarly, smooth transitions and relatively large fillet radius can be achieved for larger values of the APC valve, this is shown in Fig. 13(b).

The strength of etched samples also has a dependence on surface roughness and, therefore, it is important to determine appropriate operating conditions to control this response. Fig. 14 shows the correlation of the averaged surface roughness with the etching cycle duration and APC positions. Longer etching time and lower APC position will result in lower surface roughness. Prolonged surface exposure to a fluorine-rich plasma helps to smoothen the surface. On the other hand, lower chamber pressures produced by lower APC positions reduce the concentration of etching byproducts that dissociate and redeposit, helping in this way to reduce surface roughness. This effect 


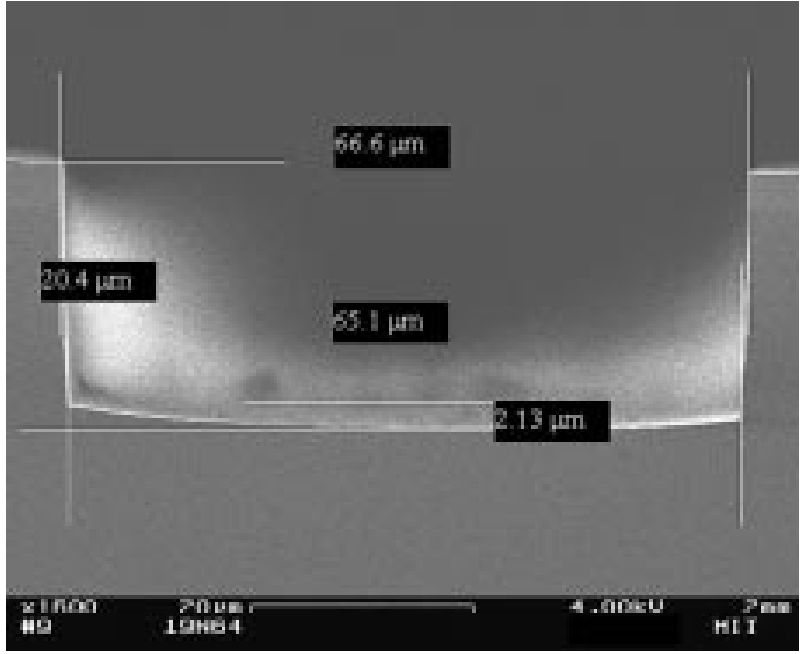

(a)

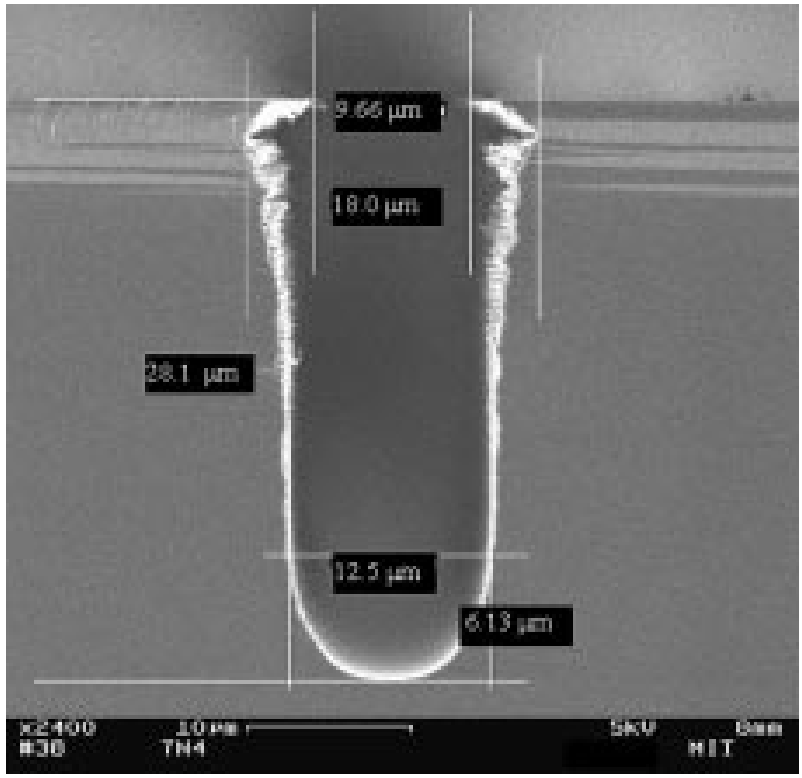

(b)

Fig. 13. (a) Relatively small fillet radius can be obtained with low APC settings. (b) SEM of a trench that exhibits a smooth transition at the feature bottom. Profile obtained with the APC valve set at $80^{\circ}$.

can be observed in Fig. 5. The etched surface shows deleterious effects due to high APC setting. However, while operating conditions with larger pressure settings are preferred to obtain larger fillet radii, lower pressure settings benefit surface roughness. For those applications where both fillet radius and surface roughness are important, a compromise has to be reached.

\section{B. Correlation Between Fracture Strength and Surface Roughness}

Fig. 15 shows the correlation between fracture strength and the averaged surface roughness. There are 55 data points in the plot. Each point represents the reference strength of a specific specimen set (16 in total). As a result, a total of 880 specimens were used to generate the data. It shows that for operating conditions that produce high surface roughness, the fracture strength is always low. For operating conditions that produce low surface roughness, the results are quite scattered. However, it is

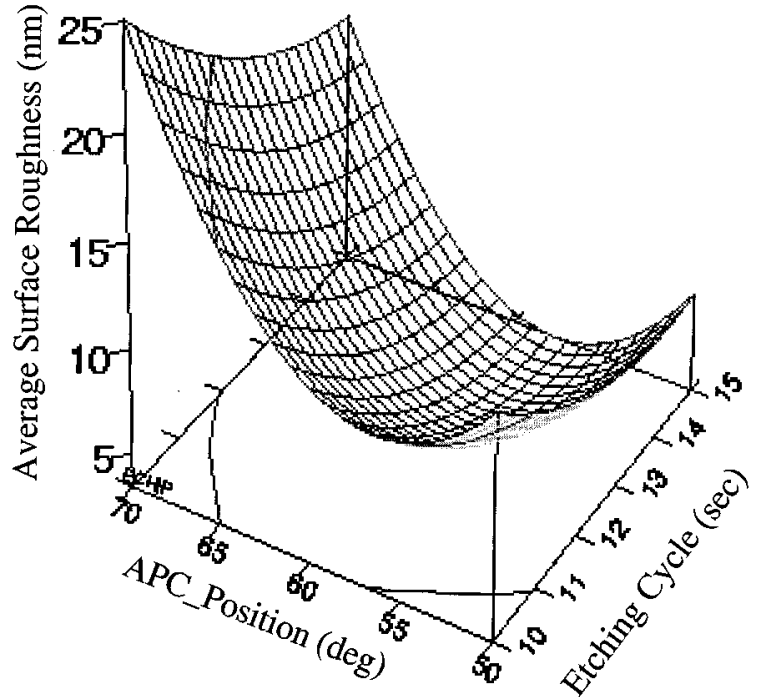

Fig. 14. Surface roughness dependence on the duration of the etching cycle and the position of the APC valve $\left(^{\circ}\right)$.

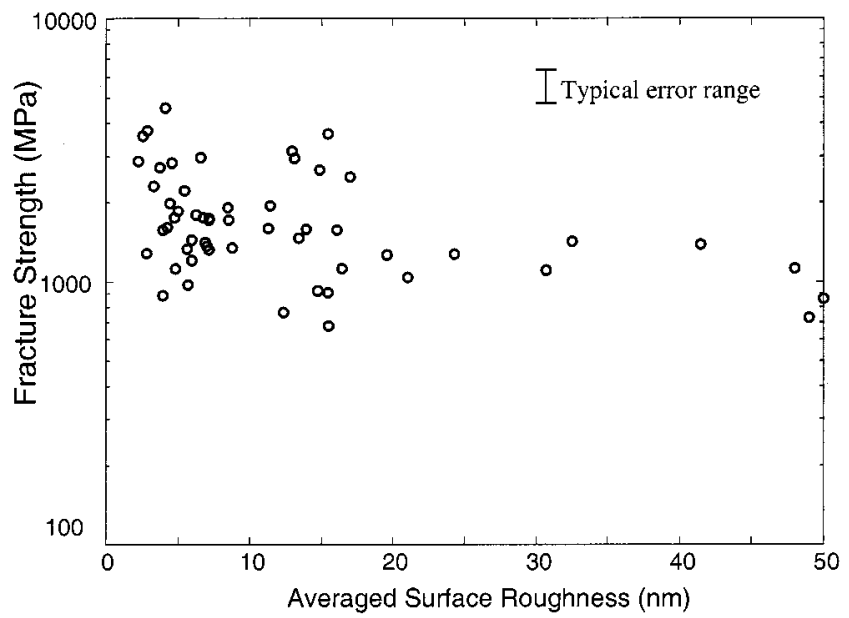

Fig. 15. Correlation between surface roughness and fracture strength. Each data point represents the reference strength of a specific wafer and was obtained by resulting 16 specimens. A total of 880 specimens were tested to construct this graph.

possible to obtain specimens with a higher fracture strength. In other words, for specimens with high surface roughness, the reference strength is lower but the strength is much more uniform (i.e., higher Weibull modulus). On the other hand, for low surface roughness specimens, the reference strength is higher but with greater scatter (i.e., lower Weibull modulus). The fracture strength actually depends on the critical flaw size instead of the surface roughness although a rougher surface indicates potentially a larger flaw size. It might not be straightforward to make a deterministic correlation between these two quantities. Also, the surface under inspection by AFM, although very close to the fillet, is not necessarily the fracture surface. It is very difficult to obtain quantitative surface roughness data at fillets due to significant variation in flatness near trench fillets. The significant scatter shown in Fig. 15 can also be explained by the intrinsic flaw approach commonly used in determining inert strength for macro scale brittle structures [29]. It can be assumed that there are two kinds of surface flaws at a fillet region. The first kind is directly caused by the DRIE process and it is correlated to 
surface roughness. The other one, however, is due to other unknown effects such as handling and damage from post-DRIE processes. Flaw size dominates the fracture behavior of brittle materials. For the low strength specimens, the flaw size induced by the DRIE process dominates. As a result, the existence of the second kind flaw has less effect on the fracture strength. This results in less of the scatter in strength. On the other hand, for these low surface roughness specimens, the DRIE process-induced flaw size is small. In the situation where the second kind of flaws are small, very high strengths can be achieved. However, if the specimen contains larger flaws due to non-DRIE effects, the strength can be seriously reduced, i.e., for low surface roughness specimens, the second kind flaw dominated the behavior. Note that for the same brittle material subject to the same processing, it is a dilemma to achieve both high strength and high uniformity. Special attention on process control or extra proof testing are usually required to increase the uniformity and average strength of the final products.

\section{APPLICATIONS}

Traditionally, MEMS structure geometries have been restricted by either the thickness limitation imposed by thin film processes or surface micromachining techniques, or the size that can be achieved by bulk micromachining. Furthermore, LIGA or LIGA-like schemes were the only ways to achieve high aspect ratio structures. However, the latter approaches are expensive, time consuming, and less amenable to integration with most semiconductor devices. The introduction of DRIE technology and its capability to create quickly small and high aspect ratio features in single crystal silicon has significantly enhanced the flexibility of MEMS fabrication. However, unlike traditional bulk or surface micromachining processes, which have been studied intensively, there have been few reports focused on the process details of DRIE. It was important to have a comprehensive study to quantify the effect of parameter variation in process performance in order to transform this technology into a more well-developed, standard MEMS fabrication process. The major contribution of this paper, therefore, is to serve as a general processing guide for processes involving DRIE. Two specific device development programs that employ DRIE processes are outlined below to illustrate the relevance of this study.

\section{A. Micro Engine Program}

This is the main motivation for this study. Technical details of silicon micro-engines can be found elsewhere [2], [5]. In order to achieve the required performance, the DRIE process must be capable of creating 200-500- $\mu$ m-deep trenches with an aspect ratio of 20:1 or higher and within a reasonable etching time. A high degree of anisotropy is also required for the operation of high-speed air bearings. Therefore, the results of this work must be extended to deeper etches. An etch performance study based on the results of this article and extended to the range of 300-500- $\mu$ m-etch depths can be found elsewhere [30].

Additionally, in order to withstand the high stresses generated during operation, the fracture strength of the structures must be well above the operating stress level (typically, around $1 \mathrm{GPa}$ ).
This imposes requirements on virtually all performance factors addressed in the previous sections. One important feature of currently available DRIE etchers is that they allow users to modify dynamically the processing parameters during a particular etch. In other words, different operating conditions could be applied to the same topographic features throughout a particular etch. This possibility makes this study even more useful. For example, operating conditions that result in a high degree of anisotropy and with a high silicon etching rate could be applied in the early stage of a deep etch to meet the demands of air bearings. During the final stages, operating conditions could be changed to yield better surface quality and smoother fillet radii to meet the requirements of structural integrity.

\section{B. Micro Solid-State Hydraulic Transducers (MSHT)}

This program also utilizes DRIE to create very high aspect ratio structures for actuation. The main purpose of this device is to convert external mechanical load into electricity via piezoelectric actuation and hydraulic rectification. Technical details, can be found elsewhere [9]. A 500- $\mu$ m-deep ring must be etched and the strength of the silicon must be able to withstand the high stresses $(\sim 1.5 \mathrm{GPa})$ generated from large deformation of the membrane. The results of this paper also make a significant contribution for process refinement during product development.

\section{SUMMARY AND CONCLUSION}

DRIE is a very versatile tool, which allows the fabrication of HARS with an anisotropy comparable to LIGA but with a technology similar to the well-known RIE. Additionally, the tool has the built-in capability to deposit fluorocarbon films in situ that may find application for electrostatic actuation and for soft-lithography techniques. However, except for a few previous studies on the effect of processing conditions on etching performance [12], [31], there have not been comprehensive studies on the sensitivity of etching performance to processing conditions. As a consequence, the selection of DRIE process parameters was usually determined heuristically and with no clear guidance for process optimization.

In this paper, a systematic etching study for a DRIE system was presented in order to explore the dependence of etching performance with respect to processing parameters. The dependence of silicon etching rate, photoresist removal rate, uniformity, anisotropy, and surface morphology on etching conditions for a time multiplexed inductively coupled plasma etcher has been characterized. In addition, the dependence of silicon fracture strength after processing was also studied experimentally. It was found that these observables are sensitive to etching parameters such as applied coil or electrode power, reactant gas flow rates, duty cycles, and chamber pressures. These results were curve fitted into a response surface to construct empirical models for process optimization.

The silicon fracture strength and surface morphology observed after etching are important for MEMS design. The dependence of achievable fillet radius and surface roughness on etching parameters such as coil power and chamber pressure has been identified. The correlation between fracture strength and surface roughness has been observed. It should be noted 
that there is a trade off between surface roughness and the achievable fillet radii in terms of APC position. Higher APC positions result in larger fillet radii and higher surface roughness. A compromise must be reached in terms of optimizing processing parameters. The test results reported herein have important implications for the development of highly stressed microfabricated structures and other MEMS applications, which utilize DRIE as the major tool for fabrication.

\section{ACKNOWLEDGMENT}

The authors would like to acknowledge their former colleagues K. Lohner, T. Melconian, and M. Kepets for their assistance in carrying out the experiments. Technical discussions with and valuable suggestions from Prof. M. Schmidt of MIT are greatly appreciated. The cooperation of the staff of the Microsystems Technology Laboratories (MTL), the Technology Laboratory for Advanced Composites (TELAC), and the Center for Material Sciences (CMSE) at MIT are also acknowledged.

\section{REFERENCES}

[1] E. H. Klaasen, K. Petersen, J. M. Noworolski, J. Logan, N. I. Maluf, J. Brown, C. Storment, W. McCulley, and G. T. A. Kovacs, "Silicon fusion bonding and deep reactive ion etching: A new technology for microstructures," Sens. Actuators, vol. A52, pp. 132-139, 1996.

[2] A. H. Epstein and S. D. Senturia, "Macro power from micro machinery," Science, vol. 276, p. 1211, 1997.

[3] P. J. Hesketh and J. D. Harrison, "Micromachining: The fabrication of microstructures and microsensors," Electrochem. Soc. Interface, vol. 3, pp. 21-30, 1994.

[4] R. B. Bosch Gmbh, U.S. Pat. 4855017, U.S. Pat. 4784720, and Germany Pat. 4241 045C1, 1994

[5] A. H. Epstein, S. D. Senturia, G. Anathasuresh, A. A. Ayón, K. Breuer, K.-S. Chen, F. E. Ehrich, G. Gauba, R. Ghodssi, C. Groshenry, S. Jacobson, J. H. Lang, C.-C. Lin, A. Mehra, J. M. Miranda, S. Nagle, D. J. Orr, E. Piekos, M. A. Schmidt, G. Shirley, S. M. Spearing, C. S. Tan, and I. A. Waitz, "Power MEMS and microengines," in Proc. 9th Int. Conf. Solid-State Sensors and Actuators (Transducers'97), Chicago, IL, June 16-19, 1995, pp. 753-756.

[6] R. L. Bayt, A. A. Ayón, and K. S. Breuer, "A performance evaluation of MEMS-based micronozzles," in Proc. 33rd AIAA/ASME/SAE/ASEE Joint Propulsion Conference \& Exhibit, Seattle, 1997.

[7] A. A. Ayón, K. S. Chen, K. A. Lohner, S. M. Spearing, H. H. Sawin, and M. A. Schmidt, "Deep reactive ion etching of silicon," Mater. Res. Soc. Symp. Proc., vol. 546, pp. 51-61, 1999.

[8] A. H. Epstein, S. D. Senturia, O. Al-Midani, G. Anathasuresh, A. A. Ayón, K. Breuer, K.-S. Chen, F. E. Ehrich, E. Esteve, L. Frechette, G. Gauba, R. Ghodssi, C. Groshenry, S. A. Jacobson, J. L. Kerrebrock, J. H. Lang, C.-C. Lin, A. London, J. Lopata, A. Mehra, J. M. Miranda, S. Nagle, D. J. Orr, E. Piekos, M. A. Schmidt, G. Shirley, S. M. Spearing, C. S. Tan, Y.-S. Tzeng, and I. A. Waitz, "Micro-heat engines, gas turbines, and rocket engines-The MIT Microengine Project," in 28th AIAA Fluid Dynamics Conference and 4th AIAA Shear Flow Control Conference, Snowmass Village, CO, June 29-July 2, 1997.

[9] H. Q. Li, D. C. Roberts, J. L. Steyn, K. T. Turner, J. A. Carretero, O. Yaglioglu, Y.-H. Su, L. Saggere, N. W. Hagood, S. M. Spearing, M. A. Schmidt, R. Mlcak, and K. S. Breuer, "A high frequency high flow rate piezoelectrically driven MEMS micropump," in Tech. Digest, IEEE Solid-State Sensor and Actuator Workshop, Hilton Head, SC, June 4-9, 2000, pp. 69-72.

[10] A. Kelly and N. H. Macmillan, Strong Solid, 3rd ed: Clarendon Press, 1986, p. 19.

[11] P. Chen and M. H. Leipold, "Fracture toughness of silicon," Am. Cream. Soc. Bulletin, vol. 59, pp. 469-472, 1980.

[12] A. A. Ayón, R. Braff, C. Lin, H. H. Sawin, and M. A. Schmidt, "Characterization of a time multiplexed inductively coupled plasma etcher," J. Electrochemical Society, vol. 146, pp. 339-349, 1999.

[13] K.-S. Chen, A. A. Ayón, and S. M. Spearing, "Tailoring and testing the fracture strength of silicon at the mesoscale," J. American Ceramic Society, vol. 83, pp. 1476-1484, 2000.
[14] — " "Silicon strength testing for mesoscale structural applications," in Mater. Res. Soc. Symp. Proc., vol. 518, 1998, pp. 123-130.

[15] M. Hu, "Critical stress in silicon brittle fracture, and effect of ion implantation and other surface treatments," J. Appl. Phys., vol. 53, pp. 3576-3580, 1982.

[16] C. J. Wilson and P.A. Beck, "Fracture testing of bulk silicon microcantilever beams subject to a side load," J. Microelectromech. Syst., vol. 5, pp. $142-150,1996$

[17] Surface Technology Systems.. USA Inc., Redwood, CA. [Online]. Available: http://www.stsystems.com/.

[18] K. D. Allen, H. H. Sawin, and A. Yokozeki, "The plasma etching of polysilicon with $\mathrm{CF}_{3} \mathrm{Cl} /$ Argon discharges," J. Electrochem. Soc., vol. 133, pp. 2331-2338, 1986.

[19] I. Tepermeister, N. Blayo, F. P. Klemens, D. E. Ibbotson, R. A. Gottscho, J. T. C. Lee, and H. H. Sawin, "Comparison of advanced plasma sources for etching applications-Part I: Etching rate, uniformity, and profile control in a helicon and a multiple electron cyclotron resonance source," J. Vac. Sci. Technol., vol. B12, pp. 2310-2321, 1994.

[20] G. S. Oehrlein, J. F. Rembetski, and E. H. Payne, "Study of sidewall passivation and microscopic silicon roughness phenomena in chlorinebased reactive ion etching of silicon trenches," J. Vac. Sci. Technol., vol. B8, pp. 1199-1211, 1990.

[21] D. C. Gray, I. Tepermeister, and H. H. Sawin, "Phenomenological modeling of ion-enhanced surface kinetics in fluorine-based plasma etching," J. Vac. Sci. Technol., vol. B11, pp. 1243-1257, 1993.

[22] D. C. Gray, "Beam simulation studies of plasma-surface interactions in fluorocarbon etching of $\mathrm{Si}$ and $\mathrm{SiO}_{2}$," Ph.D. dissertation, Massachusetts Institute of Technology, Cambridge, MA, USA, 1992.

[23] D. Mannos and D. Flamm, Plasma Etching: Academic Press, 1989.

[24] M. Pichot, "Dry processing in microelectronics: Toward low pressure plasma technology," Vacuum, vol. 41, pp. 895-898, 1990.

[25] P. H. Singer, "Today's plasma etch chemistries," Semiconductor International, March 1988.

[26] K.-S. Chen, A. A. Ayón, K. A. Lohner, M. A. Kepets, T. K. Melconian, and S. M. Spearing, "Dependence of silicon fracture strength and surface morphology on deep reactive ion etching parameters," in Mat. Res. Soc. Symp. Proc., vol. 546, 1999, pp. 21-26.

[27] W. Weibull, "Ing. Vetenskaps Akad. Handl.,", no. 151, p. 45, 1939.

[28] N. N. Nemeth, J. M. Manderscheid, and J. P. Gyekenyesi, , NASA TP-2916, 1990.

[29] B. Lawn, Fracture of Brittle Solids, 2nd ed: Cambridge University Press, 1993, pp. 263-276.

[30] A. Ayón, X. Zhang, and R. Khanna, "Anisotropic silicon trenches $300 \mu \mathrm{m}$ to $500 \mu \mathrm{m}$ deep employing Time Multiplexed Deep Etching (TMDE)," Sensors and Actuators, vol. A91, pp. 381-385, 2001.

[31] J. Hopkins, H. Ashraf, J. Bhardwaj, A. Hynes, I. Johnston, and J. Shepherd, "The benefits of process parameter ramping during the plasma etching of high aspect ratio silicon structures," in Mater. Res. Soc. Symp., vol. 605 , pp. 63-68.

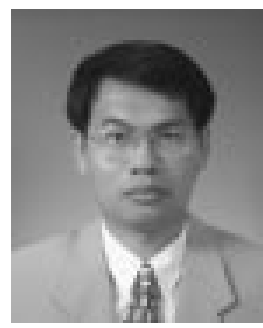

Kuo-Shen Chen received the B.S. degree in power mechanical engineering from National Tsing-Hua University, Hsinchu, Taiwan, in 1989 and the M.S. degree (in the area of precision design and control) and Ph.D. degree (in the area of MEMS and mechanics) degrees in mechanical engineering from Massachusetts Institute of Technology (MIT), Cambridge, in 1995 and 1999, respectively. His $\mathrm{Ph} . \mathrm{D}$. research focused on the material characterization, structural design, and fabrication process optimization of micro gas turbine engine.

From 1998 to 1999, he was a Postdoctoral Associate in the Active Materials and Structures Laboratory (AMSL) at the Department of Aeronautics and Astronautics of MIT, where he worked on developing the overall system dynamics of a piezo-based micro energy harvester. In addition, he also focused on the failure analysis of thick PECVD oxide, which is one of the critical issues in developing high-power density MEMS devices. Since August 1999, he has been with the Department of Mechanical Engineering, National Cheng-Kung University, Tainan, Taiwan, as an Assistant Professor. His research interests are in mechanics, materials science, and mechatronics: including mechanical analysis and material characterization in MEMS, thermomechanical modeling for micro fabrication processes, experimental mechanics for electronics packaging, system dynamics and control of mechatronics and MEMS, and structural control of smart structures. 


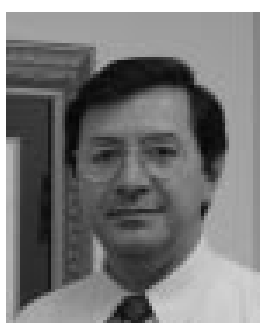

Arturo A. Ayón (S'93-M'95-SM'00) received the B.S. degree in electronic engineering from Universidad de Guadalajara, Mexico, in 1983 and the Ph.D. degree in nuclear science and engineering from Cornell University, Ithaca, NY, in 1996.

In 1983, he joined the IBM Computer Manufacturing Facility in Guadalajara, Mexico as a Manufacturing Engineer. In the same year, he moved to Rochester, MN, to serve as Liaison Engineer between the IBM manufacturing plant in Mexico and the IBM development plant in United States. In 1985, he was appointed Manufacturing and Quality Engineering Manager and returned to Mexico to oversee the operation of the newly installed manufacturing lines for computer systems. In 1986, he opened a marketing and distribution center for plastic commodities in Guadalajara, Mexico. He later sold that operation to return to graduate school to Cornell University. Between 1996 and 2000 he was a Research Scientist at the Massachusetts Institute of Technology, Cambridge. He was involved in the development and fabrication of microturbomachinery and power generation microdevices. In 2000, he joined Sony Semiconductor San Antonio, TX, as MEMS Business Development Manager to initiate, coordinate and oversee the involvement of that site in the emerging MEMS markets. His interests include deep reactive ion etching, wafer bonding, low-k dielectrics, thin-film properties, and the application of MEMS technology to RF, optics and power generation.

Dr. Ayón is a member of the American Vacuum Society, the Electrochemical Society, the IEEE Electron Devices Society, and the Materials Research Society.

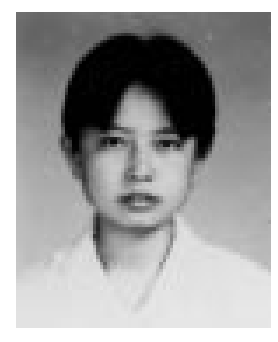

Xin Zhang (M'00) received the B.S. and M.S. degrees in materials science and engineering from Northeastern University, Shenyang, China, in 1991 and 1994, respectively. She received the Ph.D. degree in mechanical engineering from Hong Kong University of Science and Technology, Hong Kong, in 1998. Her Ph.D. research focused on residual stress and mechanical properties of thin films for MEMS applications.

From 1998 to 2001, she was a Postdoctora Associate and then a Research Scientist in the Microsystems Technology Laboratories at the Massachusetts Institute of Technology (MIT), Cambridge, where she worked on the development of a micro gas turbine engine. In November 2001, she joined the faculty of Boston University, Boston, MA, as an Assistant Professor, where her primary appointment is in the Department of Manufacturing Engineering, with a joint appointment in the Department of Aerospace and Mechanical Engineering. This position is one that is designated as a Fraunhofer faculty appointment, and offers opportunities through association and collaboration with the Fraunhofer USA Center for Manufacturing Innovation. Her research interests include Power MEMS, advanced microfabrication technologies, mechanical issues and materials science in MEMS, new materials and processes for MEMS, and assembly, packaging and reliability of MEMS devices.

Dr. Zhang is a member of the IEEE Electron Devices Society, the Materials Research Society, the Electrochemical Society, the American Vacuum Society, the American Physical Society, and the American Society of Materials.

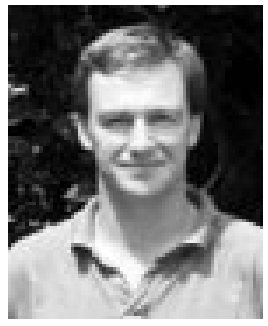

S. Mark Spearing received the Ph.D. degree from Cambridge University Engineering Department in 1990 . He worked as a research engineer at University California, Santa Barbara from 1990 to 1992, where he produced analytical models for the failure of high-temperature ceramic materials and for Carborundum Microelectronics, where he was a member of the electronic packaging technology development team from 1992 to 1994.

$\mathrm{He}$ is an Associate Professor of Aeronautics and Astronautics at the Massachusetts Institute of Technology (MIT), Cambridge, where he has been since 1994. His technical interests include materials and structural analysis and design of MEMS, electronic packages and advanced composites. Since 1995, he has been responsible for materials, structural design and packaging tasks of the MIT MicroEngine, $\mathrm{Mi}$ croRocket, Micro-chemical power, and MicroHydraulic transducer projects as well as conducting cross-cutting underpinning technology development. 